\title{
REGIONAL TOPONYMS IN TOURISM DISCOURSE ${ }^{1}$
}

\author{
Dmitriy Yu. Ilyin \\ Volgograd State University, Volgograd, Russian Federation
}

\begin{abstract}
The publication presents the practical application of research results of the regional toponyms.
The development of tourism is manifested in the increase in the print advertising for tourists - encyclopedias, guidebooks, tour guides, and increases the requirements for the quality of its content. The toponymic names, which make it possible to explicate some of the features of the spiritual and material life of the people, to provide additional information about the development of the Russian language are of particular significance in the texts of tourism discourse.

The article deals with the toponymic names the formation of which is influenced by both intra- and extralinguistic factors. The study is based on the material of onyms indicating geographical names. The author allocates the groups of regional geographical proper names, which are the basis of the nomination on the following attributes: a reflection of the natural-geographical name of conditionality; an indication of the people or peoples living in the given territory; determinism of historical figures who played a significant role in the life of the region, or the events that influenced the development of the country; ethnocultural certainty; an implicit reference to the names of the components implemented only within the region. On the basis of the description of structural and functional properties of propriation units designating geographical objects, the author shows features of their semantic content, defining their role in representative presentation of tourism discourse.
\end{abstract}

Key words: modern Russian language, onomastics, toponymy, tourism discourse, language of the region.

УДК $811.161 .1 ’ 373.21$

ББК $81.411 .2-316$
Дата поступления статьи: 29.09.2016

Дата принятия статьи: 31.10 .2016

\section{РЕГИОНАЛЬНЫЕ ТОПОНИМИЧЕСКИЕ НАЗВАНИЯ В ТУРИСТИЧЕСКОМ ДИСКУРСЕ ${ }^{1}$}

\author{
Дмитрий Юрьевич Ильин \\ Волгоградский государственный университет, г. Волгоград, Российская Федерация
}

\begin{abstract}
Аннотация. В публикации представлены возможности практического применения результатов исследования регионального топонимикона.

Развитие туристической деятельности проявляется в увеличении количества подготавливаемой для туристов печатной рекламной продукции - энциклопедий, путеводителей, экскурсионных справочников - и повышает требования к качеству ее содержания. Особую значимость в текстах туристического дискурса приобретают топонимические наименования, дающие возможность эксплицировать некоторые особенности духовной и материальной жизни населения определенной территории, представить дополнительные сведения о развитии русского языка.

В статье рассмотрены топонимы Волгоградской области и охарактеризованы интра- и экстралингвистические факторы, влияющие на их образование. Выделены группы региональных географических имен с собственных, в основу номинации которых положены следующие признаки: отражение природно-геограС. рии; детерминированность историческими личностями, игравшими значительную роль в жизни региона, или событиями, повлиявшими на развитие страны; этнокультурная определенность; указание на имплицитный компонент названия, реализуемый только в пределах данного региона. На основе описания структурнофункциональных свойств онимов, обозначающих географические объекты, показаны особенности их смыслового наполнения, определяющие их роль в репрезентации туристического дискурса.
\end{abstract}


Ключевые слова: современный русский язык, ономастика, топонимика, туристический дискурс, язык региона.

\section{1}

Туризм как сфера интернациональной культурно-опосредованной коммуникации репрезентируется в туристическом дискурсе, где находят проявление социо- и лингвокультурные особенности письменного и устного общения. К жанрам туристического дискурса В.А. Митягина относит «путеводители, энциклопедические статьи и книги об определенных странах, городах, достопримечательностях, статьи в периодических изданиях, на сайтах туристических агентств и т. П., которые существенно расширяют дискурсивный кругозор туриста» [4, с. 89]. От качества понимания туристами языковых единиц, использованных, например, в путеводителе, «зависит не только успех маркетинговых стратегий, но и формирование образа “чужой” страны в сознании иностранцев, стереотипизация инокультурных реалий» [5, с. 60]. Топонимические названия, распространенные в регионе и содержащие локально ориентированный компонент в значении, могут дать возможность носителям другого языка и иной культуры представить константы русской истории, богатство русской культуры и полифонию русского духа.

Учитывая возрастающую роль Волгоградской области как одного из центров туризма, рассмотрим географические названия этого региона в аспекте возможности их репрезентации в туристическом дискурсе. Географические наименования, распространенные в Волгоградской области как территории позднего заселения, представляют собой значительный пласт культуры, отражающий менталитет народа и его этническое своеобразие.

2

Опираясь на проведенные нами исследования регионального топонимикона, определяемого как «совокупность лексем, которые используются для наименования географических объектов, расположенных на данной территории, и, отражая особенности конкретной местности, обладают своеобразным семан- тико-смысловым потенциалом, реализуемым в процессе функционирования» [2, с. 64], представим возможности практического применения их результатов в аспекте туристической деятельности. Итоги лингвистического анализа ономастического материала, основу которого составляют архивные документы, газетные публикации и картографические данные, подкрепленные общими сведениями исторического характера, дают возможность объяснить местные названия, содержат такую топонимическую и лингвокультурологическую информацию, которая может привлечь туристов в Волгоградскую область, поскольку «на основе русской топонимии могут быть воссозданы те характерные для данного региона географические и культурные черты, которые включены в сферу “топонимического видения”, то есть могут отражаться и в местных субстратных названиях» [3, с. 48]. В связи с этим авторам текстов, формирующих туристический дискурс, необходимо, как представляется, обратить внимание туристов на национально-культурное своеобразие географических названий региона в совокупности лингвистической информации и информации, которая «принадлежит не к числу строго научных, а к числу обыденных знаний» [1, с. 7].

2.1. Включение топонимической единицы в туристический путеводитель по Волгоградской области может сопровождаться комментарием, содержащим историко-этимологическую и лингвокультурологическую информацию о проприативе. Географические имена собственные имеют разную природу. Так, наиболее распространены в регионе названия, в основу которых положены признаки, отражающие природно-географическую обусловленность названия. В частности, в кругу наименований со значением «административно-территориальные единицы, города и другие населенные пункты» представлены проприативы, основой номинации для которых послужила лексическая единица cmenь в значении «обширное, безлесное, ровное, покрытое травянистой растительностью пространство в полосе сухого климата» 
(СРЯз, т. 4, с. 262): это два поселка и три хутора с названием Степной.

Погружение в историю региона, посещаемого иностранными туристами, невозможно без включения в туристический материал справки, которая объясняла бы гостям связь ономастической и общеупотребительной лексики. Так, названия водоемов, входящие в состав наименований со значением «водные пространства, водоемы», могут этимологически восходить к обозначениям населенных пунктов. Эти особенности выявляются нами на основе анализа контекстов употребления рассматриваемых топонимов, например: Невесть с каких времен журчит светлыми водами, петляет по неоглядной придонской степи Аксай Есауловский (Волгоградская правда, 09.09.1998); По расчетам, донская вода, поднявшись, должна была по руслу Аксая Курмоярского приблизиться к городским окраинам и сделать речку судоходной (Волгоградская правда, 31.10.1998). Наличие при онимах лексических единиц журчит, вода позволяет идентифицировать характер географического объекта как водоем. Предикат журчит в составе первого предложения имеет значение «производить монотонный булькающий звук, шум (о текущей воде)» (СРЯз, т. 1, с. 489), что дает возможность квалифицировать водоем как постоянный водный поток с естественным течением, то есть реку. Гидронимы Аксай Есауловский и Аксай Курмоярский различаются уточняющими определениями, коррелирующими с названиями станиц Есауловская, Верхнекурмоярская и Нижнекурмоярская. Происхождение прилагательного Есауловский дает основания предположить, что гидроним образован от названия станицы, находившейся неподалеку от устья реки, а в основу наименования населенного пункта положено слово есаyл со значением «в царской армии: казачий офицерский чин, равный капитану в пехоте, а также лицо, носившее этот чин» (СРЯз, т. 1, c. 467), что указывает на казачье поселение в данной местности. Прилагательное Курмоярский этимологически может быть соотнесено с тюркским словов курман (или курманльюк) в значении «жертва, жертвоприношение» $[7$, c. 184] и свидетельствует о полиэтническом составе населения региона, совместном проживании славянских и тюркских народов.
2.2. Другая группа топонимов, которые могут быть включены в туристические издания, объединяет онимы, которые являются не только названием специфических реалий региона, но и «достаточно определенным и существенным признаком конкретного этноса» $[6$, с. 10]. Знаковая природа топонимов как единиц языка детерминирует обязательное наличие фоновых знаний в структуре их значения. Е.М. Верещагин и В.Г. Костомаров, выделяя в смысловой структуре онима национально-культурный компонент, полагают, что он «свойствен именам собственным, пожалуй, даже в большей степени, чем апеллятивам» $[1$, c. 56]. Помимо этого, в представлении каждого человека определенное географическое название связано с известным местом и эпохой. Это пространственное распределение топонимов позволяет им быть представителями и «хранителями» значительной культурной информации. На формирование топонимической лексики оказывает влияние фактор историчности географических наименований, так как каждое название может быть объяснено с точки зрения происхождения. Среди проприативов встречаются такие, в основу названия которых положен признак исторической закономерности наименований. Так, в группе топонимов со значением «административно-территориальные единицы, города и другие населенные пункты» встречается указание на историю возникновения топонима: село Новая Полтавка, хутор Киевка, деревня Харьков$\kappa a$ как названия на территории области говорят о том, что первые жители в эти населенные пункты пришли с Украины, поскольку корневые морфемы этих онимов по своей структуре соответствуют названиям украинских городов Полтава, Киев, Харьков.

2.3. Средством привлечения иностранных туристов в Волгоградский регион могут являться топонимические единицы, названия которых обусловлены какими-либо историческими событиями или личностями, что, несомненно, вызовет интерес к противоречивой истории нашего края. Подобные географические имена собственные имеются только в составе топонимов со значением «административно-территориальные единицы, города и другие населенные пункты». Это, в частности, онимы, которые связаны с прежним уст- 
ройством российского общества и относятся к так называемым «советизмам», в частности, поселок Красный Пахарь, поселок Большевик, поселок имени XIX партсъезда, село Колхозная Ахтуба и пр.

Общественно-социальная целесообразность использования топонима также находит выражение только в кругу наименований со значением «административно-территориальные единицы, города и другие населенные пункты», что обнаруживается прежде всего в первые послереволюционные десятилетия $\mathrm{XX}$ в. при переименовании географических объектов. В частности, в 1919 г. село Пришиб получило название город Ленинск по имени вождя пролетариата, казачья станииа Усть-Медведиикая в 1933 г. была преобразована в город Серафимович по имени уроженца этой станицы - советского писателя А.С. Серафимовича; казачья станица Преображенская в 1936 г. переименована в поселок городского типа Киквидзе в память о Василии Киквидзе, начальнике дивизии, участвовавшей в боях с белоказаками на Дону во время гражданской войны, а в 1999 г. прежнее название - Преображенская - было возвращено. Старые названия сохраняются в народной памяти. Например, в текстах СМИ встречаем контексты, где употреблены оба соотносимых топонима, причем старое название дается как основное, а новое - как пояснение: Творческую группу уже ждали в Усть-Медведицкой (Серафимовиче). Устьмедвединцы не могут простить земляку, что при жизни он воздвиг "памятник» самому себе, отняв историческое имя у родной станииы (Волгоградская правда, 01.10.1998); Еще в 1987 году вступил в действие газопровод Новониколаевский ст. Преображсенская (тогда, впрочем, станица еще именовалась рабочим поселком Киквидзе) (Волгоградская правда, 11.11.1998).

Национально-культурный компонент семантики топонимов, небезынтересных иностранному туристу, характеризуется особой страноведческой репрезентативностью, поскольку ценностная оценка называемых топонимами объектов определяет место географических названий в основном словарном фонде языка. В Волгоградской области с точки зрения значимости географических объектов преоблада- ют в основном малые населенные пункты: хутора, станицы и пр., - жители которых в силу уклада жизни занимают консервативную позицию по отношению к вопросу обозначения населенных пунктов, выступают против их переименования. Так, несмотря на трансформацию общественно-политического строя, неизменными остаются названия, отражающие идеологию советского периода, имена видных деятелей прошлого, например: Реконструируется водопровод в станице Усть-Бузулукской, на очереди поселок Красный Октябрь (Волгоградская правда, 01.10.1998); Наверное, не зря дорога в поселок Ильича каждый год зарастает бурьяном и становится непроходимой для путников (Волгоградская правда, 21.10.2003).

2.4. Представление иностранцам топонимической лексики, зафиксированной в путеводителях, экскурсионных справочниках и др., дает осознание того, что этнокультурная определенность онима ярко реализуется в составе наименований со значением «административно-территориальные единицы, города и другие населенные пункты». На территории Волгоградской области, где проживает казачество, закономерно появление и функционирование онимов, образованных от существительного казак со значением «представитель военного сословия, которое складывалось на окраинах Русского государства в XV-XVII вв. из этих вольных людей, а с XVIII в. обязано было нести военную службу за льготное пользование землей» (СРЯз, т. 2, с. 13): $x y$ тор Казачий, станица Казачка. В кругу наименований со значением «водные пространства, водоемы» этнокультурная определенность гидронима может быть обусловлена диалектными обозначениями из сферы апеллятивной лексики: озеро Кужное получило номинацию от распространенного в этой местности названия болотного растения куга; река Сокарка имеет название от диалектного обозначения одной из разновидностей тополя - сокаря. В группе онимов со значением «рельеф местности, природные образования» находят отражение обычаи казаков: курган Пьяныий получил свое наименование в силу того, что именно у этой возвышенности казаки-новобранцы перед уходом в армию выпивали последнюю чарку. 


\section{РАЗВИТИЕ И ФУНКЦИОНИРОВАНИЕ РУССКОГО ЯЗЫКА}

Топонимы Волгоградской области, таким образом, - своеобразные «хранители» историко-культурной информации. В частности, известно, что данная территория является зоной позднего заселения, имевшего полиэтнический характер. Чтобы подчеркнуть обособленность русского населения и от представителей других этносов (например, поволжских немцев), и от захватчиков, которые временно поселялись на этих землях, жители давали населенным пунктам названия, включающие в свой состав прилагательное русский, и эти наименования сохранились до сегодняшнего дня, например: Поэтическая Осиповка, разделенная, благодаря переселениям сюда немиами, на Русскую Осиповку и Немеикую Осиповку, насчитывает сейчас едва ли два десятка дворов, утратив, естественно, Немеикую Осиповку (Волгоградская правда, 16.06.2004).

В туристических путеводителях Волгоградской области, как и на картах, зафиксированы наименования географических объектов, объясняемых с точки зрения так называемой народной этимологии, раскрыть которую позволяет прием трансонимизации - толкование ойконима посредством представления информации об объекте. Примером этого явления служит относящийся к группе «водные пространства, водоемы» гидроним река Ахтуба, который, по существующей легенде, получил свое название по имени ханской дочери, бросившейся в реку.

2.5. Знакомство иностранных туристов с особенностями края предполагает введение в туристический материал известных топонимических наименований, ставших определенными маркерами, знаковыми символами, позволяющими представить Волгоградскую область в кругу других регионов России. Изменению восприятия географического имени носителями языка, проживающими в данной местности, могут способствовать социальные факторы. В качестве примера такой трансформации наименования населенного пункта можно привести название города Урюпинск. Традиции коренных жителей этого города - казаков, возрождение культуры разных этнических групп населения способствуют тому, что Урюпинск упоминается в основном как центр российской периферии, образ «малой родины», например: Праздничная предновогодняя атмосфера ияарит в негласной столице российской глу- бинки - городе Урюпинске (Волгоградская правда, 26.12.2002). Нередко название Урюпинска употребляется в переносном смысле как обозначение очень отдаленного от цивилизации места - «далекая глухая провинция, захолустье» (Отин, с. 372): Надо бросить все и уехать в Урюпинск (Волгоградская правда, 26.06.2003). Наконец, ойконим Урюпинск выступает в качестве символического обозначения места развитого народного промысла по изготовлению изделий из козьего пуха и шерсти: А в Урюпинске, этой пуховой столице России, собралось более ста участников конкурса (Волгоградская правда, 25.09.2003). Коза как животное казаков - коренных жителей Урюпинска - ассоциируется в настоящее время с образом этого населенного пункта, местные жители даже поставили памятник этому животному. Как представляется, информация о такого рода топонимах может способствовать привлечению путешественников и в целом развитию туристической отрасли.

\section{3}

Таким образом, анализ регионального топонимикона позволяет на основе характеристики структурно-функциональных свойств топонимов выделить несколько групп географических имен собственных, в основу номинации которых положены следующие признаки: 1) отражение природно-географической обусловленности названия; 2) указание на народ или народность, проживающие на данной территории; 3 ) детерминированность историческими личностями, игравшими значительную роль в жизни региона, или событиями, повлиявшими на развитие страны; 4) этнокультурная определенность; 5) указание на имплицитный компонент названия, реализуемый только в пределах данного региона.

Реализация возможности показать особенности смыслового наполнения топонима при выражении ментального компонента, выявить этнокультурную информацию, которая квалифицируется как система знаний, представлений, оценок, отражающих внешний мир, в свою очередь, способствует тому, что топонимический материал в туристическом дискурсе становится более репрезентативным. В различного рода справочники, путеводите- 
Д.Ю. Ильин. Региональные топонимические названия в туристическом дискурсе

ли и энциклопедии, рассказывающие о Волгоградской области, целесообразно включать сведения о топонимах как знаках, с помощью которых иностранный турист сможет понять своеобразие русской культуры и менталитета русского народа.

\section{ПРИМЕЧАНИЕ}

1 Исследование проводится при финансовой поддержке РГНФ, проект № 15-14-34001 «Лингвистическая и транслятологическая логистика многоязычного Интернет-портала: региональный путеводитель в координатах глобализации (Волгоград и Волгоградская область)».

\section{СПИСОК ЛИТЕРАТУРЫ}

1. Верещагин, Е. М. Лингвострановедение в преподавании русского языка как иностранного / Е. М. Верещагин, В. Г. Костомаров. - М. : Наука, 1991.-246 c.

2. Ильин, Д. Ю. Топонимическая лексика в текстах региональных газет конца XIX - начала XXI века: динамические процессы / Д. Ю. Ильин. Волгоград : Изд-во ВолГУ, 2012. - 408 с.

3. Кабинина, Н. В. Семантическое моделирование и проблемы этимологизации регионального топонимического субстрата (на материале топонимии Архангельского Поморья) / Н. В. Кабинина // Известия РАН. Серия литературы и языка. - 2009. T. 68, № 2. - С. 48-53.

4. Митягина, В. А. Коммуникативные действия в туристическом дискурсе / В. А. Митягина // Иностранные языки в высшей школе. - 2009. № 4. - С. 88-97.

5. Новикова, Э. Ю. Дискурсивно обусловленный культурный трансфер в переводе путеводителя / Э. Ю. Новикова // Вестник Волгоградского государственного университета. Серия 2, Языкознание. - 2014. - № 3 (22). - C. 60-66. - DOI: http:// dx.doi.org/10.15688/jvolsu2.2014.3.7.

6. Супрун, В. И. Ономастическое поле русского языка и его художественно-эстетический потенциал / В. И. Супрун. - Волгоград : Перемена, 2000. $-172 \mathrm{c}$.

7. Энциклопедия Волгоградской области / гл. ред. О. В. Иншаков. - Волгоград : Издатель, 2007. -448 с.

\section{СЛОВАРИ}

Отин-Отин, Е. С. Словарь коннотативных собственных имен / Е. С. Отин. - М. : А Темп, 2006. -440 с.
СРЯз - Словарь русского языка : в 4-х т. / гл. ред. А. П. Евгеньева. - М. : Русский язык, 1980-1984.

\section{REFERENCES}

1. Vereshchagin E.M., Kostomarov V.G. Lingvostranovedenie $v$ prepodavanii russkogo yazyka kak inostrannogo [Linguistic Country Studies in Teaching Russian as a Foreign Language]. Moscow, Nauka Publ., 1991. 246 p.

2. Ilyin D.Yu. Toponimicheskaya leksika v tekstakh regionalnykh gazet kontsa XIX - nachala XXI veka: dinamicheskie protsessy [Toponymic Lexis in the Texts of Regional Newspapers at the End of the 19th - Beginning of the 21st Centuries: Dynamic Processes]. Volgograd, Izd-vo VolGU, 2012. 408 p.

3. Kabinina N.V. Semanticheskoe modelirovanie i problemy etimologizatsii regionalnogo toponimicheskogo substrata (na materiale toponimii Arkhangelskogo Pomorya) [Semantic Modeling and Problems of Regional Toponymic Etymology Substrate (Based on the Toponymy of Archangel Pomorye)]. Izvestiya RAN. Seriya literatury i yazyka, 2009, vol. 68, no. 2, pp. 48-53.

4. Mityagina V.A. Kommunikativnye deystviya $\mathrm{v}$ turisticheskom diskurse [Communicative Actions in the Tourism Discourse]. Inostrannye yazyki v vysshey shkole [Foreign Languages in Tertiary Education], 2009, no. 4, pp. 88-97.

5. Novikova E.Yu. Diskursivno obuslovlennyy kulturnyy transfer $\mathrm{v}$ perevode putevoditelya [Cultural Transfer in Travel Guide Translation: Discourse Approach]. Vestnik Volgogradskogo gosudarstvennogo universiteta. Seriya 2, Yazykoznanie [Science Journal of Volgograd State University. Linguistics], 2014, no. 3 (22), pp. 60-66. DOI: http://dx.doi.org/10.15688/ jvolsu2.2014.3.7.

6. Suprun V.I. Onomasticheskoe pole russkogo yazyka $i$ ego khudozhestvenno-esteticheskiy potentsial [Onomastic Field of the Russian Language and its Artistic and Aesthetic Potential]. Volgograd, Peremena Publ., 2000. 172 p.

7. Inshakov O.V., ed. Entsiklopediya Volgogradskoy oblasti [Encyclopedia of the Volgograd Region]. Volgograd, Izdatel Publ., 2007. 448 p.

\section{DICTIONARIES}

Otin E.S. Slovar konnotativnykh sobstvennykh imen [Dictionary of Connotative Proper Names]. Moscow, A Temp Publ., 2006. 440 p.

Evgenyeva A.P., ed. Slovar russkogo yazyka: v 4-kh t. [Russian Language Dictionary. In 4 vols]. Moscow, Russkiy yazyk Publ., 1980-1984. 


\section{РАЗВИТИЕ И ФУНКЦИОНИРОВАНИЕ РУССКОГО ЯЗЫКА}

\section{Information About the Author}

Dmitriy Yu. Ilyin, Doctor of Sciences (Philology), Associate Professor, Head of Department of Russian Language and Documentation Studies, Volgograd State University, Prosp. Universitetsky, 100, 400062 Volgograd, Russian Federation, dilyin99@mail.ru, iryas@volsu.ru.

\section{Информация об авторе}

Дмитрий Юрьевич Ильин, доктор филологических наук, доцент, заведующий кафедрой русского языка и документалистики, Волгоградский государственный университет, просп. Университетский, 100, 400062 г. Волгоград, Российская Федерация, dilyin99@mail.ru, iryas@volsu.ru. 